\title{
Review of: "The shape of water in zeolites and its impact on epoxidation catalysis"
}

\author{
Changqing Sun ${ }^{1}$ \\ 1 Nanyang Technological University
}

Potential competing interests: The author(s) declared that no potential competing interests exist.

Phonon spectroscopic measurements and MD simulations [234] suggest that $\mathrm{H}_{2} \mathrm{O}$ molecules form bulk-like three-dimensional structures within $1.3 \mathrm{~nm}$ cages of zeolite pores, whereas $\mathrm{H}_{2} \mathrm{O}$ molecules coalesce into oligomeric one-dimensional chains when the pore diameter falls below $0.65 \mathrm{~nm}$. Correspondingly, the $\mathrm{w}_{\mathrm{H}}$ peak evolves from two components at 3200 and $3400 \mathrm{~cm}^{-1}$ to the skin component at $3580 \mathrm{~cm}^{-1}$ only. Heating from $304 \mathrm{~K}$ to $343 \mathrm{~K}$ shift the peak from 3200 to a broad peak centered at $3500 \mathrm{~cm}^{-1}$. The reorganization of these pore-size-dependent $\mathrm{H}_{2} \mathrm{O}$ structures during alkene epoxidation catalysis gives rise to entropy gains that increase the turnover rates by up to 400 -fold.

Observations clearly indicate the effects of molecular undercoordination ${ }^{[1]}$ and thermal activation ${ }^{[2]}$ on the hydrogen bond $(\mathrm{O}: \mathrm{H}-\mathrm{O})$ cooperativity and polarizability $(\mathrm{HBCP})$ that shortens and stiffens the $\mathrm{H}-\mathrm{O}$ bond while lengthens and softens the O:H elongation. Undercoordiantion polarizes the electrons while heating depolarizes water by thermalization. The high reactivity arises from the polarization effect ${ }^{[3]}$.

\section{References}

1. `Chang Q. Sun, Xi Zhang, Xiaojian Fu, Weitao Zheng, et al. (2013). Density and Phonon-Stiffness Anomalies of Water and Ice in the Full Temperature Range. J. Phys. Chem. Lett., vol. 4 (19), 3238-3244. doi:10.1021/jz401380p.

2. `Chang Q. Sun, Xi Zhang, Xiaojian Fu, Weitao Zheng, et al. (2013). Density and Phonon-Stiffness Anomalies of Water and Ice in the Full Temperature Range. J. Phys. Chem. Lett., vol. 4 (19), 3238-3244. doi:10.1021/jz401380p.

3. `Chang Q. Sun. (2020). Water electrification: Principles and applications. Advances in Colloid and Interface Science, vol. 282 , 102188. doi:10.1016/j.cis.2020.102188. 